\title{
Nucleolar organiser regions in adenocarcinoma in situ and invasive adenocarcinoma of the cervix
}

\author{
J F Darne, S V Polacarz, E Sheridan, D Anderson, R Ginsberg, F Sharp
}

\begin{abstract}
Silver binding nucleolar regions (AgNORs) were evaluated in normal endocervix, adenocarcinoma, and its potential precursor, adenocarcinoma in situ (AIS), in an attempt to increase an understanding of the natural history of cervical adenocarcinoma and to identify a marker for abnormal endocervical (atypical glandular) cells which could aid diagnosis and follow up of endocervical lesions. For every 50 cells the mean AgNOR counts were as follows: normal endocervical cells $(n=15) 79.8$ (95\% Cl 68-91); AIS $(\mathbf{n}=20) 200 \cdot 7(95 \%$ Cl 182-219); and invasive adenocarcinoma $(n=30) 299(271-328)$. There was no overlap between the groups of normal endocervical cells and invasive adenocarcinoma, but there was significant overlap between cases of invasive adenocarcinoma and carcinoma in situ. In six out of 17 cases with AIS, NOR count in adjacent morphologically normal glandular cells ("internal" controls) was increased when compared with the "external" (normal endocervical) control group. This suggests the presence of wider field changes not previously identified using routine histological methods.

The findings suggest that AIS is a potential premalignant precursor of invasive adenocarcinoma, but that assessment of NORs is of no practical use in discriminating between the histological types of cervical carcinoma.
\end{abstract}

The absolute incidence of adenocarcinoma of the cervix seems to have increased in young women over the past decade. ${ }^{1-4}$ An increase in the proportion of adenocarcinomas in series of cervical carcinomas has also been reported. ${ }^{56}$

The natural history of cervical adenocarcinoma has been less well investigated than that of its squamous counterpart. Teshima et al suggested that adenocarcinoma could arise de novo from "normal" epithelium without passing through an adenocarcinoma in situ (AIS) phase $^{7}$; this could be explained by the underdiagnosis of AIS. ${ }^{89}$ The premalignant potential of certain lesions of the endocervix however-namely, cervical glandular atypia (CGA) and AIS-remains unclear, and their diagnosis and follow up remain difficult. ${ }^{10}$

Nucleolar organiser regions (NORs) have an essential role in the transcription of nucleic acid to protein. An apparent increase of visible NORs in a cell population seems to reflect increased transcriptional activity. NOR counts, visualised as dots using an argyrophilic technique, have been reported to help in the distinction between high and low grade lymphoma ${ }^{11}$ and benign and malignant melanomas. ${ }^{12} \mathrm{~A}$ significant difference in the number of NORs has more recently been reported when comparing benign and malignant stomach lesions, but there was some overlap between the two groups. ${ }^{13}$ The mean number of NORs has also been shown to increase steadily in cervical intraepithelial neoplasia (CIN) from grades I to III. ${ }^{14}$

The aims of this study were to use a simple silver staining technique for NOR protein to investigate the association between normal columnar epithelial cells of the endocervix, potential malignant precursors, and invasive adenocarcinoma of the cervix; and to identify a marker for abnormal endocervical (atypical glandular) cells which might enhance the diagnosis and follow up of endocervical lesions.

\section{Methods}

Archival, formalin fixed, and paraffin wax embedded tissue blocks were used. It was unlikely that any single centre would have had sufficient material in its histopathological archives to supply the number of specimens of AIS required: it was therefore essential to collect the material on a multicentre basis.

Tissue blocks from 30 women with invasive cervical adenocarcinoma and 20 with AIS (cones or punch biopsy specimens) were selected. "External" controls consisted of normal endocervical blocks of tissue obtained from 15 patients after total hysterectomy for dysfunctional uterine bleeding. All tissues studied had been previously diagnosed using routine haematoxylin and eosin staining.

Sections from the original blocks were cut at $4 \mu \mathrm{m}$, placed on glass slides, dewaxed and rehydrated. Adjacent sections from each block were stained with haematoxylin and eosin, and for argyrophilic protein-linked NOR (AgNOR), as described elsewhere. ${ }^{15}$ Briefly, all solutions used were freshly prepared using glass distilled water, and a gelatin $(2 \mathrm{~g} / \mathrm{dl})$ and formic acid $(1 \mathrm{ml} / \mathrm{dl})$ solution was vortexed with a $50 \%$ solution of silver nitrate $(1: 2$ volumes). Staining with this mixture was started shortly after mixing and carried out for 35 minutes at room temperature in a darkroom. The slides were then fixed, washed, dehydrated and mounted. The final reaction 


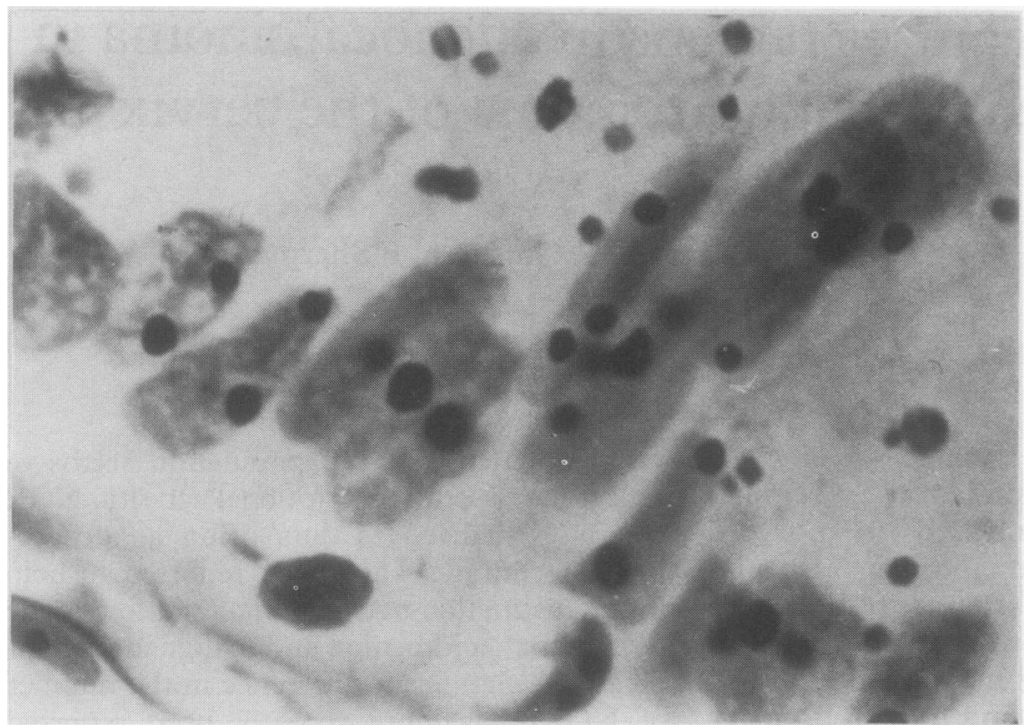

Figure 1 "External" normal endocervical control. Most cells contain one or two visible black NOR granules (black argyrophilic dots).

product, which indicates the presence of an NOR, is the appearance of a black silver granule(s) in the nucleus.

Using oil immersion (of a final magnification of 1000) "total" AgNORs present were counted in the nuclei of 50 endocervical glandular consecutive normal or atypical cells. "Internal controls" were also evaluated in the AIS subgroup-that is, morphologically normal columnar epithelium adjacent to AIS.

\section{Results}

"EXTERNAL" NORMAL ENDOCERVICAL CONTROL CELLS

Most cells contained one or two NORs which tended to be large, with regular outline, and

Figure 2 Scattergram to show distribution of total numbers of NORs for 50 cells of each case examined. Horizontal bars indicate the median for each group. evenly stained (fig 1). The median for 15 patients studied was $70 \mathrm{NORs} / 50$ cells $(95 \%$ Cl-68 to 91) (fig 2).

\section{AIS}

The median count for this group of 20 patients was 209 NORs/50 cells $(95 \%$ Cl 182 to 219). This showed a significant increase in the total number of NORs in this group when compared with those of the normal controls (Mann-Whitney U test, $\mathrm{p}<0.001$ ). Figure 2 shows a clear distinction between the external control and the AIS groups. Furthermore, individual NORs were smaller, occurring in clusters, and more widespread within the nuclei (fig 3).

Adjacent, morphologically normal glandular cells ("internal" controls) in the sections of AIS were identified and total number of NORs counted. This was possible in only 17 out of 20 cases. The median count was 98 NORs $/ 50$ cells (95\% Cl 92 to 135), significantly higher than the normal external controls. (Mann-Whitney U tests-p $<0.01$ ). A noticeable increase in NOR count in the internal controls, however was seen in six out of 17 patients. The counts in the other groups were within external control limits.

\section{INVASIVE ADENOCARCINOMA}

A significant increase in the NOR count was seen in the 30 cases of invasive adenocarcinoma compared with the AIS group (overall median 299 NORs/50 cells; $p<0.001$ ) there was, however, considerable overlap between these two tissue populations (fig 2). The abnormal features of individual NORs in the invasive adenocarcinoma sections were as described for the AIS group, or more pronounced in some cases.

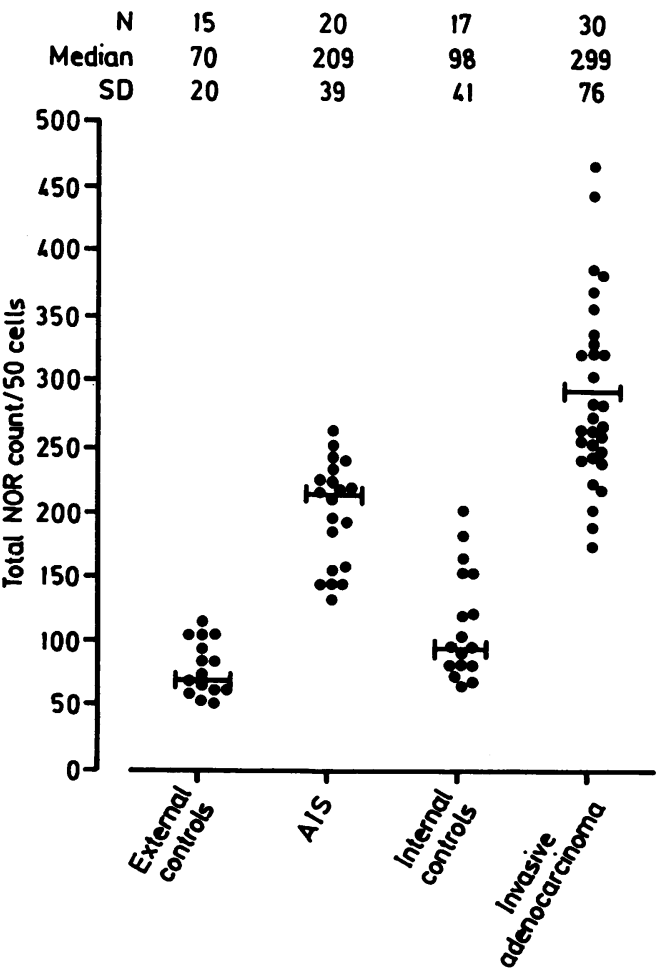

\section{Discussion}

The potential malignant role of AIS has received scant attention recently. Rollanson et al investigated the staining patterns of six cases of AIS with antiepithelial membrane antigen (anti-EMA) as part of a larger study and found that AIS and early adenocarcinoma stained equally intensely. ${ }^{16}$ Similarly, 13 out of 15 cases of cervical glandular atypia showed abnormal dense cytoplasmic and cuticular reactivity with human milk fat globulin/monoclonal antibody. ${ }^{17}$ Normal endocervix showed only dense cuticular reactivity.

Other markers have also been studied: intermediate filaments, ${ }^{18}$ carcinoembryonic antigens, and fat globule membrane antigen. ${ }^{18}$ Our study is, as far as we know, the first controlled investigation of both potential precursors and invasive disease. The numbers of NORs were significantly increased in both study groups when compared with normal columnar epithelium, thus corroborating a potential premalignant role for AIS. This further confirms the retrospective finding of glandular atypia in smears taken up to six years previously in six out of 13 cases of invasive adenocarcinoma ${ }^{19}$ and histological 


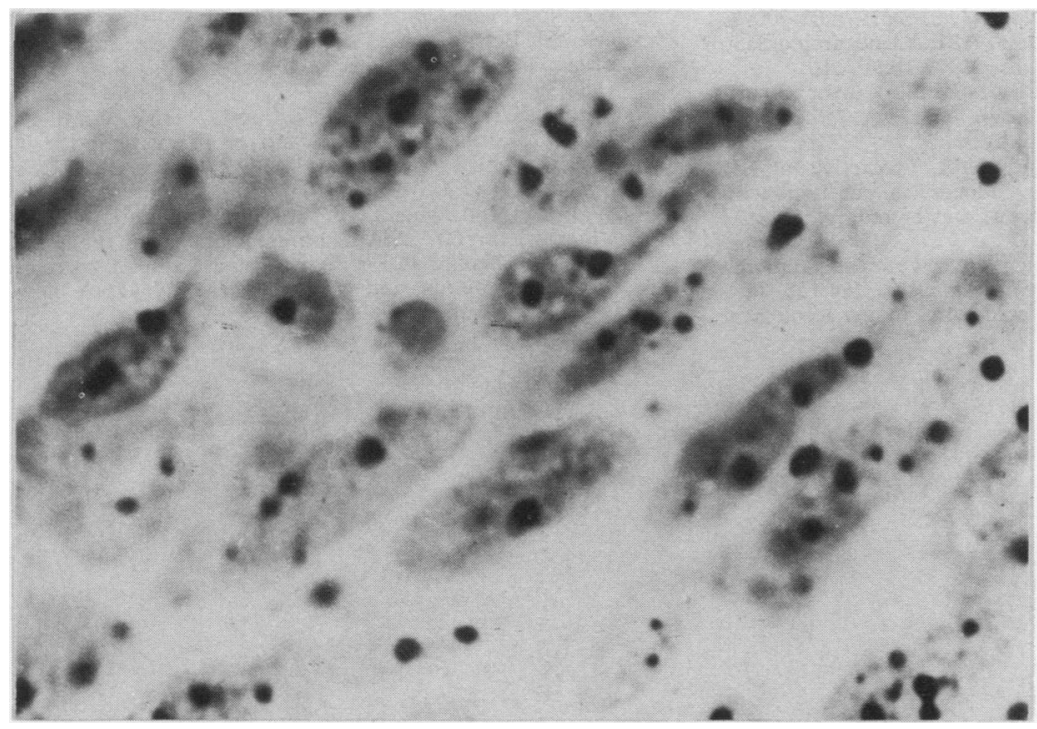

Figure 3 Adenocarcinoma in situ: most cells contain numerous visible black NOR granules. to recognise, ${ }^{24}$ probably because of inadequate experience, early invasion by AIS has been clearly described. ${ }^{25}$ Unfortunately, assessment of NORs, due the considerable overlap between AIS and invasive adenocarcinoma groups in our studies, was a poor discriminant between the two conditions. Morphometric analysis has also shown an unacceptably high degree of overlap between them, ${ }^{26}$ but similar to squamous cervical intraepithelial neoplasia, ${ }^{14}$ the median number of NORs increased steadily from AIS to invasive disease. Assessment of NORs, however, has already been shown to be of no practical use in discriminating between the histological types of cervical carcinoma ${ }^{27}$ but is thought to be of possible prognostic value in breast cancer. ${ }^{28}$

This study adds further support to the potential premalignant role that AIS has in invasive adenocarcinoma. It has also identified a potential cytological marker for endocervical lesions although assessment of NORs will be of no practical use for enhancing the diagnosis of early stromal invasion.

abnormality in five out of 18 similar cases.

The conventional management of AIS, if the margins of excision are clear of dysplastic epithelium on cone biopsy, is essentially short term colposcopic and longer term cytological follow-up. The recurrence of AIS is like the initial lesion, likely to be small in size and confined to a small area of the cervix, ${ }^{20}$ but routine cytology is known to be poor at detecting exfoliated atypical glandular cells. ${ }^{21}$ The use of an NOR count as a marker peculiar to AIS (and invasive lesions) with additional endocervical sampling, which has recently been shown to be effective in predicting residual disease in incompletely excised squamous cervical intraepithelial neoplasia, ${ }^{22}$ could improve the follow up of these lesions. After observing a significantly increased NOR count in dysplastic endocervical cells this study is being extended to address this issue.

Simple hysterectomy has been suggested as the ideal surgical management of AIS. ${ }^{2023}$ Analysis of recent data from three United Kingdom cancer registries has shown a threefold increase in cervical adenocarcinoma in 20 to 34 year olds during the 10 years studied. ${ }^{3}$ There must be a parallel increase in AIS in the same age group. Hysterectomy is most undesirable in such young women, but diagnostic cone biopsy is thought to be therapeutic if the margins of excision are clear. We observed an increase in NOR count in morphologically normal endocervical epithelium adjacent to AIS in six out of 17 cases. Using the $c-m y c$ oncogene monoclonal antibody P62, similarly abnormal gene expression or amplification was observed in nine out of 14 cases in otherwise normal glands adjacent to AIS (personal observations, Polacarz SV, Darne JF, Sharp F). These observations imply a more widespread field change and suggest that simple cone biopsy, even if margins of excision are clear, might be suboptimal treatment in some cases.

The presence of invasion clearly has important therapeutic and prognostic implications. Although controversial and extremely difficult
We thank Dr M C Anderson (The Samaritan Hospital, London), Dr A B Maclean (Hospital for Mothers, Glasgow) Mr J M Monaghan (Oncology Centre, Gateshead) and Mr I Scott (Derby City Hospital, Derby) for providing some of the Scott (Derby City Hospital, Derby) for
archival specimens used in this study. allenbach-Hellweg G. On the origina and histome

2 Ireland D, Hardiman P, Monaghan JM. Adenocarcinoma of the uterine cervix: a study of 73 cases. Obstet Gynecol 1985;65:82-5.

3 Chilvers C, Mant D, Pike MC. Cervical adenocarcinoma and oral contraceptives. Br Med J 1987;295:1446-7.

4 Vesterinen $\mathrm{E}$, Forss M, Nieninen U. Increase of cervical adenocarcinoma: a report of 520 cases of cervical carcinoma including 112 tumours with glandular elements. Gynecol Oncol 1989;33:49-53.

5 Davis RJ, Moon LB. Increased incidence of adenocarcinoma of uterine cervix. Obstet Gynecol 1975;45:79-83.

6 Gallup DG, Abell MR. Invasive adenocarcinoma of the uterine cervix. Obstet Gynecol 1977;49:596-602.

7 Teshima S, Shimosato Y, Kishi K, Ohmi K, Uei Y. Early stage adenocarcinoma of the uterine cervix. Cancer 1985;56:167-72.

8 Christopherson WM, Nealon N, Gray LA. Noninvasive precursor lesions of adenocarcinoma and mixed adenosquamous-carcinoma of the cervix uteri. Cancer 1979;44:975-83.

9 Boon ME, Baak JPA, Kurver PJH, Overtriep SH, Verdouk GW. Adenocarcinoma in situ of the cervix: an underdiagnosed lesion. Cancer 1981;48:768-73.

10 Wells M, Brown LJR. Glandular lesions of the uterine cervix: the present state of knowledge. Histopathol 1986;10:777-92.

11 Crocker J, Nar P. Nucleolar organiser regions in lym phomas. J Pathol 1987;151:111-8.

12 Crocker J, Silbeck N. Nucleolar organiser region associated protein in cutaneous melanotic lesions: a quantitative study. J Clin Pathol 1987;40:885-9.

13 Suarez V, Newman J, Hiley C, Crocker J, Collins M. The epithelium of the stomach. Histopathol 1989;14:61-6.

14 Egan M, Freeth MG, Crocker J. CIN, HPV infection and nucleolar organiser regions in cervical epithelium. Abstract 80. 156th Meeting of the Pathology society, 1988. London: Pathology Society, 1988

15 Smith R, Crocker J. Evaluation of nucleolar regionassociated proteins in breast malignancy. Histopathol 1988;12:113-25.

16 Rollanson TP, Byrne P, Williams A, Brown G. Expression of epithelial membrane and 3-fucosyl-N-acetyl-lactosamine antigens in cervix uteri with particular reference to adenocarcinoma in situ. $J$ Clin Pathol 1988;41:547-52.

17 Brown LJR, Griffin NR, Wells M. Cytoplasmic reactivity with the monoclonal antibody HMFGI as a marker of cervical glandular atypia. J Pathol 1987;151:203-8.

18 Dabbs DJ, Geisinger KR, Norris HT. Intermediate filaments in endometrial and endocervical carcinomas. $A m$ J Surg Pathol 1986;10:568-76.

19 Boddington MM, Spriggs AI, Cowdell RH. Adenocarcinoma of the uterine cervix: cytological evidence of a long structure of adenocarcinoma of endocervix in wom
under 50 years of age. Path Res Pract 1984;179:38-50. value of NOR numbers in neoplastic and non-neoplastic 
preclinical evolution BrJObstet Gynaecol 1976;83:900-4. 20 Weisbrot IM, Stablinsky C, Davis AM. Adenocarcinoma in situ of the uterine cervix. Cancer 1972;18:807-10.

21 Peete CH, Carter B, Cherry WB, et al. Follow up of patients with adenocarcinoma of the cervix and cervical stump. $\mathbf{A m}$ J Obstet Gynecol 1965;93:343-56.

22 Husseinzadek N, Shbaro I, Wesseler T. Predictive value of cone margins and post-cone endocervical curettage with residual disease in subsequent hysterectomy. Gynecol Oncol 1989;33:198-200.

23 Quazilbash AH. In-situ and micro-invasive adenocarcinoma of the uterine cervix. Am J Clin Pathol 1975;64:155-70.

24 Burghardt E. Microinvasive carcinoma in gynaecological pathology. Clin Obstet Gynecol 1984;11:239-57.

25 Clark AH, Betshill WL. Early endocervical glandular neoplasia. 11. Morphometric analysis of cells. Acta Cytol 0:127-34.

26 Newbold KM, Rollanson TP, Luesley DM, Ward K. Nucleolar organiser regions and proliferative index in glandular and squamous carcinoma of the cervix. J Clin Pathol 1989;42:441-2.

27 Giri DD, Nottingham JF, Lawry J, Dundas SAC, Underwood JCE. Silver binding nucleolar organiser regions in benign and malignant breast lesions: correlations with ploidy and growth phase by DNA flow cytometry. J Pathol 1989;157:307-13. 